\title{
SISTEM INFORMASI PETIR (SIP) DENGAN METODE LIGHTNING DISTRIBUTION (LD) DI WILAYAH SUMATERA BARAT
}

\author{
Andrew Kurniawan Vadreas*, Primas Emeraldi**, Ariadi Hazmi** \\ *Mahasiswa S2 Teknik Elektro Univertsitas Andalas \\ ** Teknik Elektro Universitas Andalas
}

\begin{abstract}
Abstrak-Paper ini memetakan 200 lokasi sambaran petir di daerah Sumatera Barat. Pemetaan lokasi sambaran petir sebagai bagian dari Sistem Informasi Petir (SIP) dirancang dengan metode Lightning Distribution (LD). Lokasi sambaran petir diperoleh menggunakan metode refleksi ionosfer untuk mengetahui jarak sambaran petir dari stasiun pendeteksi petir dan metode Magnetic Direction Finding (MDF) untuk mendapatkan arah dari sambaran petir. Data arah kemudian diproses untuk menghasilkansuatulokasikejadianpetir, kemudian lokasitersebutakan ditampilkan pada Google Maps. Setelah itu di proses dengan metode Lightning Distribution yang merupakan bentuk pemetaan kerapatan sambaran petir dengan menggunakan "Format File grid", dimana setiap grid diukur sebesar $1 \mathrm{x} 1 \mathrm{~km}^{2}$ yang disebut dengan Local Flash Density (LFD). Jika terdapat beberapa titik sambaran pada satu grid akan merubah warna yang ada pada peta sesuai seberapa banyak jumlah sambaran pada satu grid yang merupakan perhitungan Probabilistic Flash Density (PFD). Penggambaran besarnya skala bahaya petir berupa variasi perubahan warna pada titik sambaran dimana warna hijau mewakili jumlah minimum kerapatan sambaran yang berisikan satu titik sambaran dan warna merah mewakili jumlah maximum kerapatan sambaran yang berisikan lebih dari sepuluh titik sambaran. Berdasarkan warna distribusi sambaran petir daerah Kabupaten Agam dan Payakumbuh memiliki tingkat sambaran petir tertinggi pada periode penelitian ini.
\end{abstract}

Kata kunci : refleksi ionosfer, magnetic direction finding (MDF), lightning distribution, sistem informasi petir, dangoogle maps API.

\begin{abstract}
This paper mapped 200 locations of lightning strikes in West Sumatra province. Mapping the location of lightning strikes as part of Lightning Information System was designed with the method of Lightning Distribution (LD). To get the location of lightning strikes obtained from the calculation reflection of ionosphere method to determine the distance of a lightning strike from stations of lightning and methods of Magnetic Direction Finding (MDF) to get directions from the lightning strike. Direction data obtained processed to generate a lightning incident location, then that location will be displayed on Google Maps. After that in the process of Lightning Distribution method which is a form of lightning strike density mapping by using the "File Format" grid, where each grid was measured to be $1{\mathrm{x} 1 \mathrm{~km}^{2}}^{2}$ called the Local Density Flash (LFD). If there are multiple point strikes on the grid will change the color that is on the map fit how many number of strikes on the grid which is a Probabilistic computation Flash Density (PFD). The depiction of the scale of danger lightning in the form of variations color changes at the point where the bolt of green color represents the minimum number density of lightning strikes that contains a single point and the red color represents the maximum number density of strikes which contains more than ten points strike. Based on the color distribution of lightning strikes and Payakumbuh Agam area has the highest rate of lightning strikes in the study period.
\end{abstract}

Key words: reflection ionosphere, magnetic direction finding (MDF), lightning distribution, lightning information system, and google maps API.

\section{PENDAHULUAN}

Perubahan iklim yang semakin ekstrim dari tahun-ketahun mengakibatkan berbagai macam bencana alam salah satunya petir. Petir merupakan suatu proses peristiwa di atmosfir berupa pelepasan muatan listrik dari awan bermuatan. Pada saat pelepasan muatan ini menuju suatu objek, yang kita sebut dengan sambaran petir. Mengingat adanya kemungkinan kerusakan akibat sambaran petir cukup berbahaya, salah satunya terhadap jaringan listrik [1]. 
Berbagai upaya dilakukan untuk mengatasi masalah tersebut, oleh karena itu dibutuhkan suatu sistem yang dapat memberikan informasi kerawanan sambaran petir pada suatu daerah untuk mendapatkan nilai-nilai kerawanan sambaran petir sehingga bisa dipetakan secara digital. Dalam penelitian ini diharapkan suatu model peta menggunakan Sistem Informasi Geografis (SIG).

Di Sumatra Barat sendiri perlu suatu sistem pemantauan petir untuk melihat kondisi daerahnya yang banyak terjadi petir, sulitnya pengumpulan informasi tanpa adanya suatu sistem komunikasi data yang saling terintegrasi menjadi kebutuhan bagi para peneliti akan informasi petir karena pentingnya data visual untuk menginterprestasikan data numerik dari suatu kejadian petir.

Dalam berbagai penelitian yang selama ini dilakukan untuk mencari kerawanan sambaran petir salah satunya menggunakan metode Simple Additive Weighting (SAW) yaitu analisis keputusan multi kriteria dengan metode penjumlahan terbobot [2]. Metode ini melakukan analisis dengan mengumpulkan data sambaran petir lebih kurang selama 10 tahun untuk mendapatkan hasil. Maka dari itu bisa dilihat dari waktu penelitian yang relatif lama dalam mengumpulkan data. Tapi dengan menggunakan metode Lightning Distribution (LD) bisa mempercepat waktu dalam pengolahan karena dalam metode ini mengolah data secara real time dimana saat terjadinya sambaran petir data langsung masuk kedalam sistem yang kemudian diolah menjadi Sistem Informasi Petir.

Kebutuhan akan informasi mengenai sambaran sangat penting dalam perancangan bangunan suatu daerah. Kejadian petir yang tidak dapat diprediksi membutuhkan data informasi petir yang terjadi didaerah tersebut.

Jadi Sistem Informasi Petir (SIP) adalah penggambaran besarnya skala bahaya petir. Data SIP didapat dari peta tingkat kerawanan bahaya sambaran petir sehingga bisa digunakan untuk mengurangi resiko akibat sambaran. Pada daerah dengan tingkat kerawanan bahaya sambaran petir yang tinggi tentunya diupayakan untuk mendirikan bangunan bangunan dengan struktur tahan sambaran petir atau memperhitungkan jika terjadi sambaran petir kita bisa meminimalisir korban [3].

Dalampembuatan Sistem Informasi Petir ini melibatkan beberapa komponen sistem diantaranya

a. Sistem Informasi Geografis (SIG)

Suatu sistem yang dapat mendukung pengambilan keputusan spasial dan mampu mengintegrasikan deskripsi-deskripsi lokasi dengan karakteristik-karakteristik fenomena yang ditemukan di lokasi tersebut. Pengintegrasian SIG merangkul dan merepresentasikan sistem informasi lainnyamenggunakan teknologi komputer untuk mengintegrasikan, memanipulasi dan menampilkan informasi yang ada di suatu area geografi, lingkungan, dan karakteristik yang mengikuti suatu daerah geografi yang digunakan oleh berbagai bidang ilmu [4].

\section{b. Google Maps API}

Sebagai media pemetaan sistem informasi geografis pada penelitian ini merupakan layanan gratis Google yang cukup popular yang merupakan library JavaScript.

\section{c. PHP (Personal Home Page Hypertext Preprocessor) \\ PHP merupakan bahasa pemrograman} berbasis web dengan menggunakan server. Seluruh aplikasi berbasis web dapat dibuat dengan PHP. Namun kekuatan yang paling utama PHP adalah pada konektivitasnya dengan system database di dalam web.

Sistem database yang dapat didukung oleh PHP antara lain :
1. Oracle
2. $M y S Q L$
3. Ms. Access
4. Sybase
5. PostgreSQL
d. APACHE

\section{METODE PENELITIAN}

Metode Lightning Distribution merupakan bentuk pemetaan kerapatan sambaran petir dengan menggunakan "Format File grid", dimana setiap grid diukur sebesar $1 \times 1 \mathrm{~km}^{2}$ yang disebut dengan Local Flash Density (LFD), jika terdapat beberapa titik sambaran pada satu grid akan merubah warna yang ada pada peta sesuai seberapa banyak jumlah sambaran pada satu grid yang merupakan perhitungan probabilitas dari kerapatan sambaran petir [5].

Hitungan dalam Metode Lightning Distribution :

- Setiap grid perhitungan waktu $1 \mathrm{grid} / \mathrm{km}$ LFD [6].

Untuk menentukan Format File grid, dimana setiap grid diukur sebesar 1 x $1 \mathrm{~km}^{2}$ yang disebut dengan LFD. Baik pada DMS (degree minute second) maupun DD (decimal degree), perlu diketahui berapa ketelitian pada suatu nilai kordinat. Karena di wilayah katulistiwa jarak $1^{\mathrm{o}}$ sama dengan jarak 111,321 km. Maka perlu diperhatikan kesalahan yang terjadi jika kita mengabaikan suatu angka menit atau detik pada DMS atau suatu nilai digit dalam kordinat DD

Karena pada DMS, $1^{\circ}=3600^{\prime \prime}=111,321$ $\mathrm{km}$, maka 1" kira-kira sama dengan jarak $30 \mathrm{~m}$. Maka perubahan nilai kordinat sebesar 1" berarti penyimpangan jarak sejauh $30 \mathrm{~m}$. Andai jika kita 
bisa mentolerir kesalahan sampai $100 \mathrm{~m}$, berarti kesalahan kordinat tidak boleh lebih besar dari 3,3". Pada sistem DD, juga perlu diperhatikan jarak yang diwakili oleh setiap digit di belakang koma. Perubahan satu satuan pada digit pertama di belakang koma mempunyai nilai jarak lebih dari 11 Km. Perubahan satu unit pada digit kedua di belakang koma berarti $1,1 \mathrm{~km}$. Demikian seterusnya.Berarti jika kita hanya mentolerir kesalahan sampai $100 \mathrm{~m}$, maka kordinat DD harus dibuat setidaknya sampai 4 digit di belakang koma.

Karna pada google maps menggunakan DD jadi dapat dihitung dalam $1 \mathrm{~km}$ didapatkan dari hasil DD (decimal degree) adalah 0,0089830310543384 dari pembagian $1^{\circ}$ dibagi dengan 111,321 km setidaknya dalam koordinat DD mengambil 4 digit dibelakang koma sehingga didapatkan sebesar $0,0089^{\circ}$ dalam satuan DD (decimal degree).

- Focal Flash Density (FFD) merupakan defenisi dari segala bentuk aktivitas dan evaluasi dari resiko sambaran petir terhadap bangunan [7].

Proses dalam penentuan FFD dibedakan dalam 4 kategori bahaya :

1. (ND) Sambaran pada bangunan ND= Ng.Ad.Cd.10-6

2. (NM) Sambaran ketanah "dekat" bangunanNM $=$ Ng.Cd.10-6

3. (NL) Sambaran Kejaringan Listrik terhubung bangunan

4. (NI) Sambaran "dekat" jaringan listrik yang terhubung bangunan

Dimana :

Ad $=$ luas daerah efektif sambaran $\left(\mathrm{km}^{2}\right)$

$\mathrm{Ng}=$ kerapatan sambaran petir ke tanah (sambaran $/ \mathrm{km}^{2}$ tahun).

Dimana $\mathrm{Cd}$ merupakan lokasi relative yang dibedakan antara 4 :

1. objek yang dikelilingi objek-objek yang tinggi atau pohon-pohon dengan nilai $\mathrm{Cd}$ $(0,25)$

2. Objek yang dikelilingi oleh objek-objek yang rendah atau pohon-pohon dengan nilai $\mathrm{Cd}(0,50)$

3. Tidak adanya objek-objek sekitar daerah sambaran petir dengan nilai $\mathrm{Cd}$ (1)

4. Terpisah dari Objek di puncak bukit dengan nilai $\mathrm{Cd}(2)$

Dengan demikian kita dapat menjelaskan dampak/ akibat sambaran petir terhadap Konstruksi bangunan, fungsi bangunan, penghuni dan pusat pelayanan.

- $\quad$ Probabilistic Flash Density (PFD) bertujuan untuk lebih mempertimbangkan kemungkinan yang terjadi dari hasil-hasil yang didapat dari LFD dan FFD [8].

Begitu juga halnya dalam Estimasi PFD. Dengan Elips probabilitas yang bertujuan untuk lebih mempertimbangkan kemungkinan dari hasilhasil yang didapat dari LFD dan FFD, dalam kinerja elips probabilitas dipisahkan dalam 10\% 99\% irisan elips (dalam hitungan distribusi gaus). Dalam satu grid bisa terdiri dari

beberapa banyak irisan elip dengan jumlah ketebalan irisan yang berbeda. Mosd ditelas:
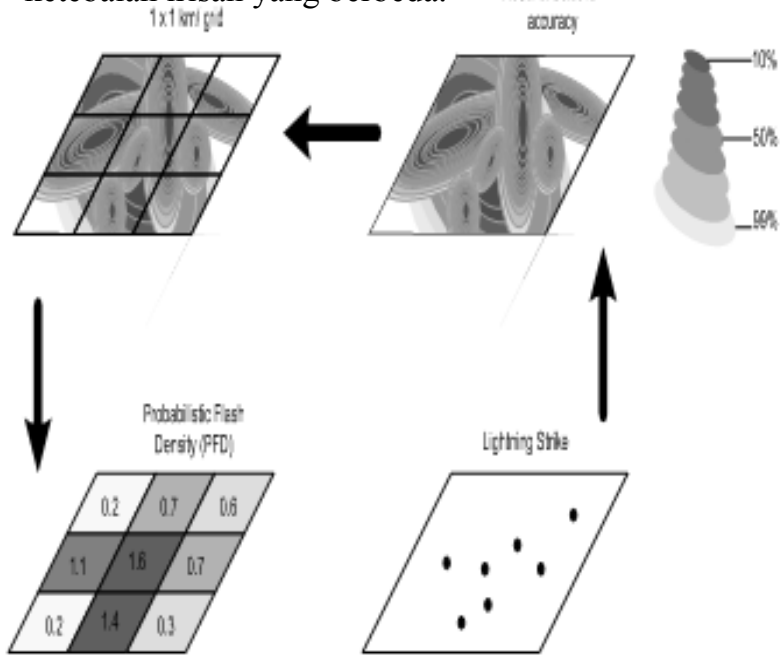

Gambar 2.1. Estimasi PFD [8].

Perancangan SIP dimulai dengan disain input data yang dikirimkan oleh stasiun pendeteksi sambaran petir (sensor medan magnet petir) melalui PicoScope yang merupakan hardware yang akan membaca data analog dari stasiun pendeteksi sambaran petir yang kemudian mengubahnya kedalam data digital, yang diolah dengan menggunakan metode refleksi ionosfer untuk mencari jarak sambaran petir dari stasiun petir dan metode Magnetic Direction Finder (MDF) untuk mendapatkan arah dari sambaran petir. Data arah yang dihasilkan dikumpulkan dan diproses sehingga menghasilkan suatu lokasi kejadian petir.

Setelah itu data disimpan kedalam database yang akan dipetakan dan ditampilkan ke google maps dengan website secara online. Dalam menampilkan sambaran petir yang dipetakan menggunakan metode LD yaitu bentuk pemetaan kerapatan sambaran petir dengan menggunakan "Format File grid", dimana setiap grid diukur sebesar 1 x $1 \mathrm{~km}^{2}$ yang disebut dengan LFD, jika terdapat beberapa titik sambaran pada satu grid akan merubah warna yang ada pada peta sesuai seberapa banyak jumlah sambaran pada satu grid 
yang merupakan perhitungan probabilitas dari kerapatan sambaran petir [5]. Proses dari perancangan SIP ini dapat dilihat pada gambar 2.2.
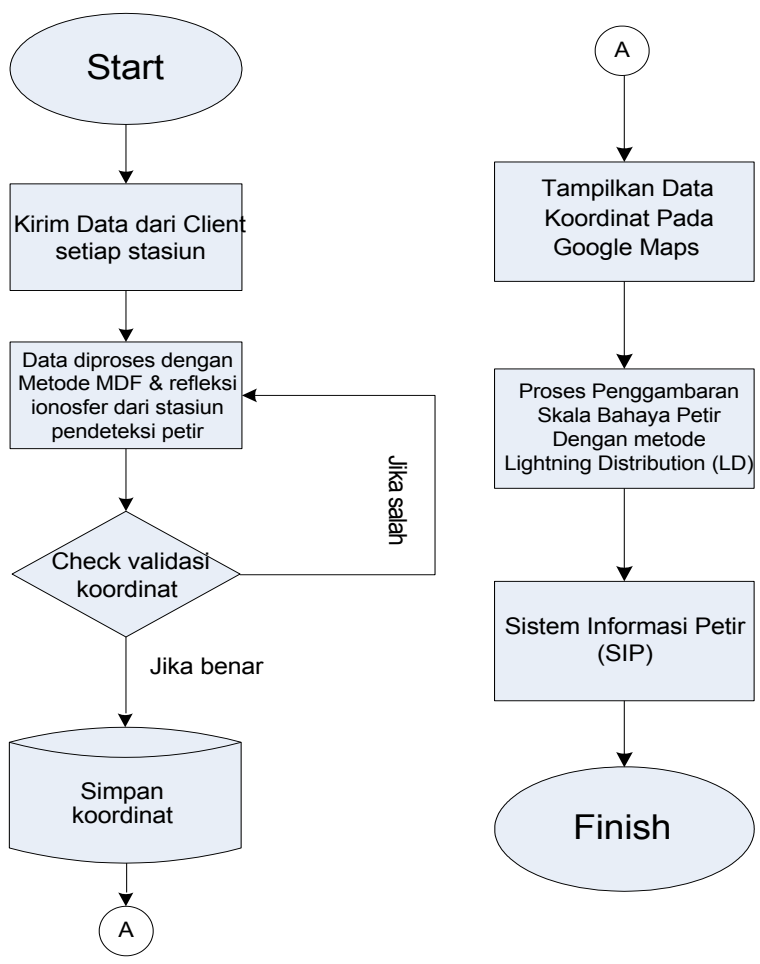

Gambar 2.2. Aliran SIP

Data analog dari stasiun pendeteksi sambaran petir diubah kedalam data digital, yang diolah dengan dua metode salah satunya dengan menggunakan metode refleksi ionosfer yang dapat dilihat pada gambar 2.3.

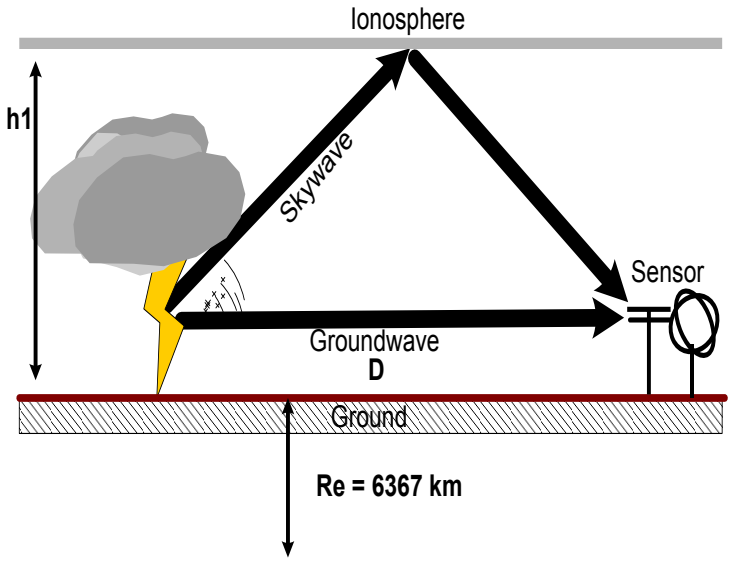

Gambar 2.3. pencarian jarak sambaran petir dengan metode refleksi ionosfer [9]
Dari gambar diatas didapatkan proses pencarian jarak sambaran petir dengan rumus [9] :

$\mathrm{h} 1=\operatorname{Re}\left[\cos ^{2}\left(\frac{D}{2 R e}\right)-1\right]+\sqrt{\left\{\operatorname{Re}^{2}\left[\cos ^{2}\left(\frac{D}{2 R e}-1\right)\right]+\left(\frac{c . t_{1}+D}{2}\right)^{2}\right\}}$

Keterangan :

h1 = tinggi refleksi ionosphere

$\mathrm{Re}=$ jari-jari bumi

$\mathrm{C}=$ kecepatan cahaya $(\mathrm{m} / \mathrm{s})$

$\mathrm{D}=$ jarak ke kanal petir

$\mathrm{t}_{1}=\mathrm{T}_{1}+\mathrm{T}_{2}$ perbedaan waktu datang first skywave dengan ground wave $(\mathrm{s})=$ 0.0002052

Aktivitas Diagram salah satu cara memodelkan event-event yang terjadi dalam suatu aplikasi web untuk visualisasi SIP menggunakan google maps yang dapat dilihat pada gambar 2.4.

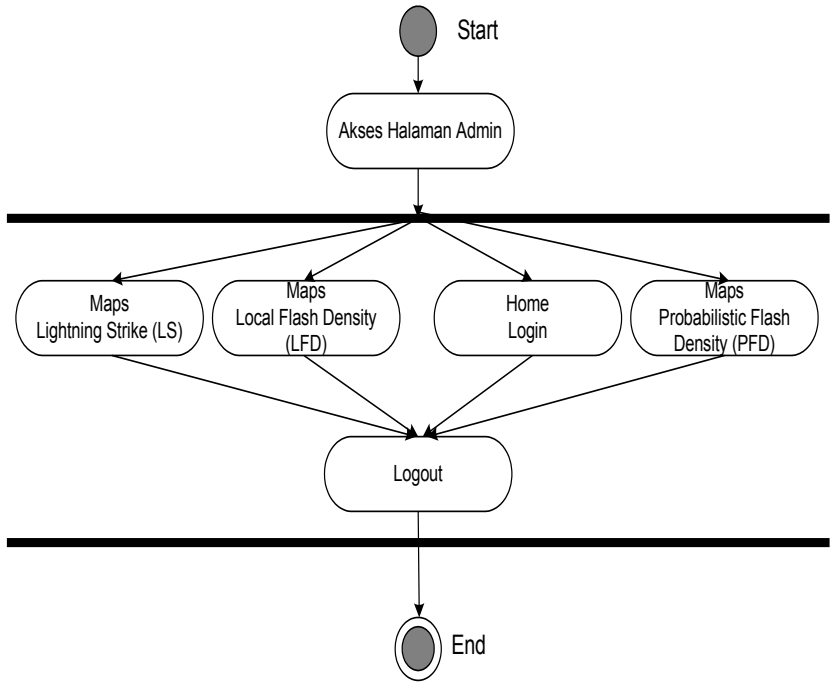

Gambar 2.4. Aktivitas Diagram Aplikasi Web SIP

\section{HASIL DAN DISKUSI}

\subsection{Hasil Pencarian LFD, FFD dan PFD dengan metode $L D$}

Pada bagian hasil dan diskusi akan menjelaskan penggambaran besarnya skala bahaya petir dengan menggunakan metode LD yang didapatkan dari proses pencarian LFD kemudian dilanjutkan kedalam proses penentuan FFD yang merupakan segala bentuk resiko sambaran petir terhadap bangunan. Sedangkan PFD bertujuan untuk lebih mempertimbangkan hasil yang didapat dari LFD dan FFD. Berdasarkan perhitungan arah lokasi petir dari masing-masing stasiun didapatkan 200 titik lokasi petir yang terekam pada tanggal 01/05/2014 - 31/07/2014, didapatkannya lokasi titik sambaran petir yang menjadi acuan dalam 


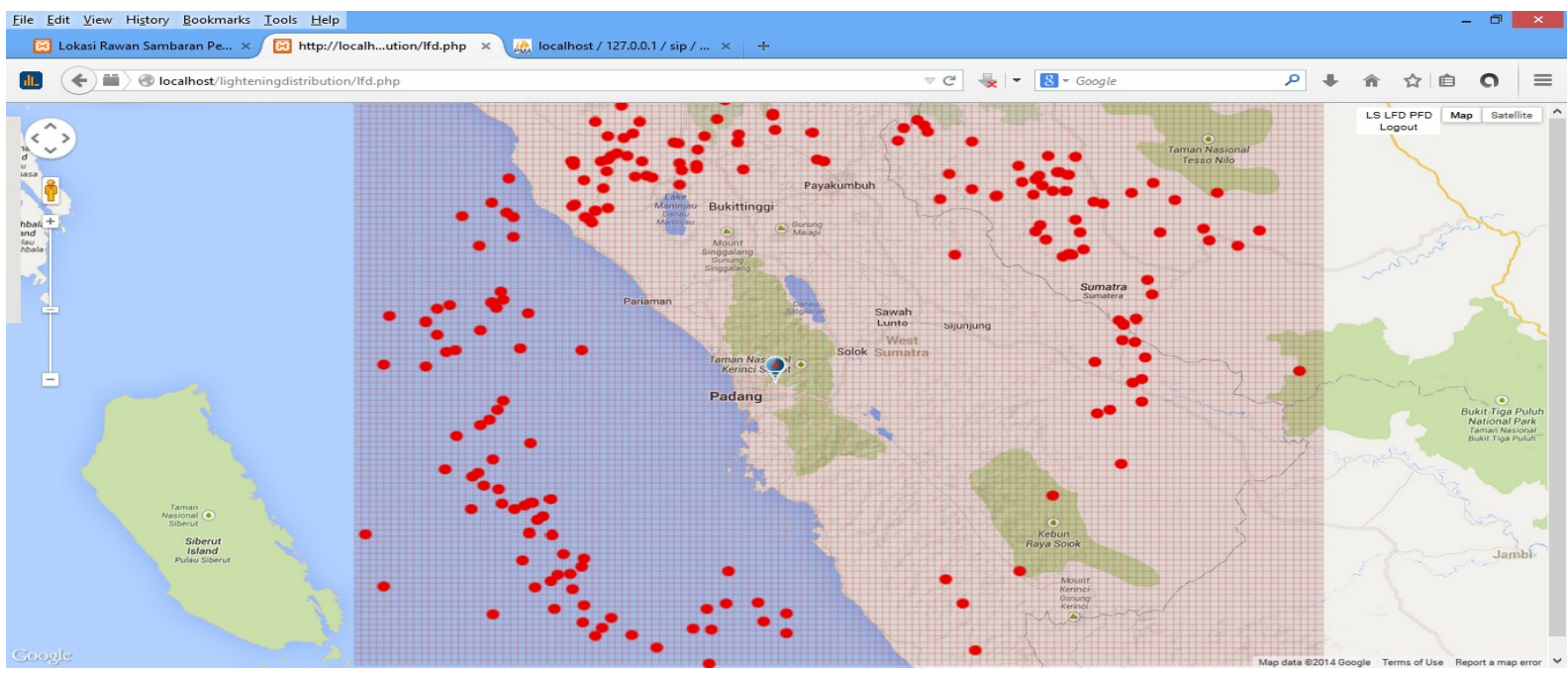

Gambar 3.1. LFD Dari Hasil 200 Data Petir Pada Tanggal 01 Mei 2014 s/d 31 Juli 2014

proses metode LD dilihat pada gambar 3.1. sebagai pemetaan yang ada pada proses pencarian LFD.

Lokasi titik sambaran dengan menggunakan LFD ini berguna untuk menggambarkan skala bahaya petir setiap gridnya. Segala bentuk resiko dari sambaran petir dicari dengan PFD yang memberikan variasi perubahan warna lokasi yang rawan sambaran petir pada setiap perubahan warna mewakili banyaknya titik sambaran yang berada pada setiap gridnya antara lain :

- Warna hijau merupakan warna minimum dari kerapatan sambaran yang berisikan satu titik sambaran.

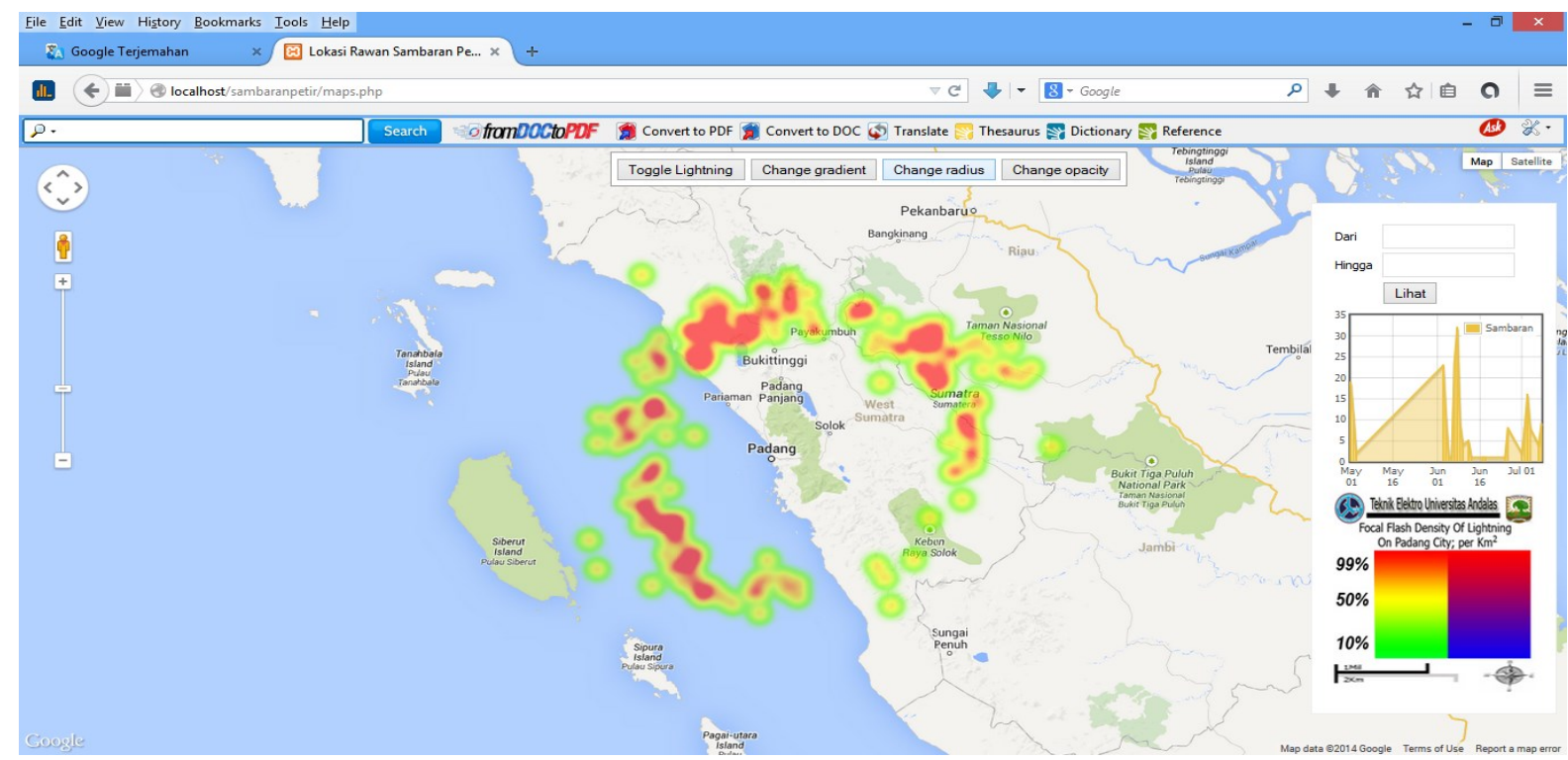

Gambar 3.2. PFD Dari Hasil 200 Data Petir Pada Tanggal 01 Mei 2014 s/d 31 Juli 2014

- Warna Kuning berisikan rata-rata lima titik sambaran dari kerapatan sambaran. 
- Warna merah merupakan warna maximum dari kerapatan sambaran yang berisikan lebih dari sepuluh titik sambaran.

Berdasarkan warna distribusi sambaran petir dapat dilihat pada gambar 3.2. daerah Kabupaten Agam dan Payakumbuh memiliki tingkat sambaran petir tertinggi pada periode penelitian ini dengan jumlah sambaran sebanyak 35 titik sambaran dari 200 titik sambaran petir.

\section{KESIMPULAN}

Berdasarkan hasil yang didapatkan dan analisa yang dilakukan dari penelitian ini, maka dapat disimpulkan beberapa hal sebagai berikut :

1. Metode LD yang dirancang dapat menampilkan lokasi petir dan penggambaran besarnya skala bahaya petir.

2. Penggambaran besarnya skala bahaya petir berupa variasi perubahan warna pada titik sambaran dimana warna hijau mewakili jumlah minimum kerapatan sambaran yang berisikan satu titik sambaran dan warna merah mewakili jumlah maximum kerapatan sambaran yang berisikan lebih dari sepuluh titik sambaran.

3. Berdasarkan warna distribusi sambaran petir daerah Kabupaten Agam dan Payakumbuh memiliki tingkat sambaran petir tertinggi pada periode penelitian ini dengan jumlah sambaran sebanyak 35 titik sambaran dari 200 titik sambaran petir.

\section{UCAPAN TERIMA KASIH}

Terimakasih diucapkan atas bantuan dan dukungan dalam penelitian ini:

- Universitas Andalas yang telah mendanai dengan BOTPN, kontrak No. 01/UN.16/PL/U-S2,S3/2014.

- Rekan-rekan mahasiswa di Laboratorium Teknik Tegangan Tinggi (TTT) Teknik Elektro Universitas Andalas yang telah membantu dalam proses penelitian.

\section{DAFTAR PUSTAKA}

[1] Husni. 2002. Mengenal Bahaya Petir.Jurnal Meteorologi dan Geofisika. Vol 3.No. 4 Oktober - Desember 2002. Jakarta.

[2] Sugiyono, Agani N. 2011. Model Peta Digital Rawan Sambaran Petir Dengan Menggunakan Metode Saw (Simple Additive Weighting) : Studi Kasus Propinsi Lampung. Magister Ilmu Komputer Program Pascasarjana Universitas Budi Luhur :
Lampung. Jurnal TELEMATIKA MKOM Vol.4 No.1, Maret 2012.

[3] Kern A, Landers UL, Diendorfer G. Die neue österreichische Blitzschutznormung (2). Available at: http: //www.aldis.at/Blitzschu tz/Blitzschutznorm_Teil2_EJ7_08.pdf (08.05.2012).

[4] Guswanto, Dasar dan Aplikasi Sistem Informasi Geografis , Badan Meteorologi Klimatologi dan Geofisika, 2007.

[5] Neuwirth C, Spitzer W and Prinz T. 2012. Lightning Density Distribution and Hazard in an Alpine Region. Available at : http://creativecommons.org/licenses/bync/3.0/ (23.10.2013).

[6] Campos D, Pinto O. Investigation about the intensity and location of the maximum cloud-to-ground lightning flash density in the city of Sao Paolo. Available at: http:// ws9.iee.usp.br/

sipdax/papersix/sessao02/2.12.pdf (08.05.2012).

[7] Kern A, Landers UL, Diendorfer G. Die neue österreichische Blitzschutznormung (2). Available at: http: //www.aldis.at/Blitzschu tz/Blitzschutznorm_Teil2_EJ7_08.pdf (08.05.2012).

[8] Diendorfer G. Some comments on the achievable accuracy of local ground flash density values. In: Conference proceedings. 29th International Conference on Lightning Protection 2008.

[9] Haddad, et.al. 2012. New measurements of lightning electric fields in Florida: Waveform characteristics, interaction with the ionosphere, and peak current estimates. JOURNAL OF GEOPHYSICAL RESEARCH, VOL. 117, D10101, doi:10.1029/2011JD017196, 2012.

\section{Biodata Penulis}

Andrew Kurniawan Vadreas lahir di Padang tahun 1987, memperoleh gelar S.Kom dari Universitas Putra Indonesia - YPTK Padang dan saat ini sedang menempuh pendidikan S2 pada Jurusan Teknik Elektro Universitas Andalas. 